\title{
EFEITO DA SALINOMICINA NA PREVENÇÃO DA ACIDOSE LÁCTICA RUMINAL EXPERIMENTAL EM OVINOS
}

\author{
AdAuCides CÂMARA ${ }^{1}$, José Augusto Bastos Afonso ${ }^{2}$, CARLA Lopes MendonÇA ${ }^{2}$, AERLEM \\ CYNNARA SILVA VIEIRA ${ }^{3}$ \\ ${ }^{1}$ Pós-graduando da Universidade Federal do Semi-Árido, Mossoró, RN, Brasil. adaucides@ yahoo.com.br \\ ${ }^{2}$ Professores Doutores da Universidade Federal Rural de Pernambuco, Recife, PE, Brasil \\ ${ }^{3}$ Pós-graduanda da Universidade Federal Rural de Pernambuco, Recife, PE, Brasil
}

\begin{abstract}
Este trabalho teve por objetivo estudar a eficácia da salinomicina na acidose láctica induzida em ovinos, analisando os seus efeitos sobre o quadro clínico e as características físico-químicas do fluido ruminal. Para tal, foram utilizados 14 animais ovinos da raça Santa Inês, com peso médio de $30 \mathrm{Kg}$, fistulados, subdivididos em dois grupos de 07 animais, sendo um o controle e o outro o que recebeu o antibiótico, na concentração de $30 \mathrm{mg} / \mathrm{Kg}$ ao dia na dieta, durante 42 dias. Nessa etapa, os padrões clínicos e laboratoriais das amostras ruminais foram estabelecidos. Ao final do período de adaptação, os dois grupos foram desafiados a um processo de acidose láctica
\end{abstract}

induzida com sacarose, na dose de $10 \mathrm{~g} / \mathrm{Kg}$ de peso vivo. As observações clínicas e laboratoriais foram realizadas nos intervalos de $4 \mathrm{~h}, 8 \mathrm{~h}, 12 \mathrm{~h}, 16 \mathrm{~h}, 24 \mathrm{~h} 32 \mathrm{~h}$ e $48 \mathrm{~h}$ pós indução (PI). Os ovinos do grupo controle e os que receberam o ionóforo apresentaram manifestações clínicas da acidose lática ruminal 8 horas após a indução, associadas às alterações laboratoriais, com intensidade variada entre os grupos estudados. Nos animais que receberam a salinomicina, verificou-se que a magnitude do processo foi minimizada e, com isso, abreviou-se o tempo de recuperação clínica em relação ao grupo controle.

PALAVRAS-CHAVE: Distúrbios fermentativos; ionóforos; pequenos ruminantes.

\section{SALINOMYCIN EFFECT ON THE PREVENTION OF RUMINAL LACTIC ACIDOSIS IN SHEEP}

\section{ABSTRACT}

The objective of this work was to study the effectiveness of salinomycin against the lactic acidosis induced in sheep, by analyzing its effects on the clinical situation, and the physico-chemical characteristics of the ruminal fluid. We used 14 crossbred Santa Ines sheep, weighing $30 \mathrm{Kg}$. They were rumen-fistulated and subdivided into two groups of 7 animals each: the control group and the group that received the drug in the diet at a concentration of $30 \mathrm{mg} / \mathrm{Kg}$ of food for 42 days. We established the clinical and laboratory values of the ruminal samples during this phase of the experiment. At the end of the adaptation period, both groups were challenged in a process of sucrose-induced lactic acidosis, at a dose of 10 $\mathrm{g} / \mathrm{Kg}$ body weight. The clinical and laboratory observations were accomplished at intervals of $4 \mathrm{~h}, 8 \mathrm{~h}$, $12 \mathrm{~h}, 16 \mathrm{~h}, 24 \mathrm{~h}, 32 \mathrm{~h}$ e $48 \mathrm{~h}$ post-induction (PI). Control and treated sheep showed clinical signs of ruminal acidosis within eight hours after induction, associated with laboratory alterations with varied intensity between the studied groups. In the animals that received salinomycin, the magnitude of the process was minimized and the time of clinical recovery was shortened in relation to the control group.

KEYWORDS: fermentation disorder; ionophores; small ruminants. 


\section{INTRODUÇÃO}

A ovinocultura nacional vem apresentando, nos últimos anos, destaque devido ao crescimento expressivo no meio agropecuário, onde grandes investimentos estão sendo aplicados. $\mathrm{O}$ rebanho ovino no Brasil é estimado em 17.662.201 de cabeças, das quais 10.110.352 encontram-se no Nordeste (IBGE, 2012). O impacto econômico e social que esse tipo de atividade representa para a região é de grande relevância, principalmente na produção de carne.

Apesar desse incremento na ovinocultura, existem alguns fatores que são considerados limitantes na sua exploração, como inadequações no manejo, melhoramento, sanidade, nutrição, entre outros. No que diz respeito à nutrição, a necessidade de um modelo de produção intensivo, com o intuito de se obter em curto prazo metas excessivas de ganho de peso, tem gerado modificações nos hábitos alimentares que podem acarretar o surgimento de distúrbios digestivos e metabólicos relacionados aos diferentes tipos de dietas empregadas. Dentre eles, destaca-se a acidose lática ruminal, por ser um entrave na criação de ovinos, limitando o crescimento, devido às perdas econômicas provocadas (MACKIE et al., 1978; BARROS et al., 1999; LEAN et al., 2007).

A acidose láctica é uma doença metabólica, cuja evolução, na maioria dos casos, é aguda, causada pela ingestão súbita de grãos ou outros alimentos ricos em carboidratos altamente fermentáveis, em grandes quantidades, caracteriza-se por perda do apetite, depressão e morte. É também conhecida por sobrecarga ruminal, indigestão aguda, compactação aguda do rúmen ou indigestão por carboidratos (AFONSO et al., 2000; MIRANDA NETO et al., 2005; WALKER, 2006).

Vários são os trabalhos publicados enfocando as práticas de medidas preventivas para o controle da acidose ruminal, desde o fornecimento adequado da dieta, até o uso de tamponantes e antibióticos, incluindo nessa categoria os ionóforos; contudo, há poucos relatos do seu emprego em animais com esse objetivo (McGUFFEY et al., 2001; AFONSO et al., 2002a; MIRANDA NETO et al., 2011). Portanto, o propósito deste trabalho foi avaliar clínica e laboratorialmente a eficácia do emprego da salinomicina na prevenção da acidose lática ruminal induzida em ovinos.

\section{MATERIAL E MÉTODOS}

O trabalho foi realizado na Clínica de Bovinos - UFRPE, no período de abril a setembro de 2007. Foram utilizados 14 ovinos machos e fêmeas, da Raça Santa Inês, com peso médio de $30 \mathrm{~kg}$, clinicamente sadios; os animais foram submetidos à intervenção cirúrgica para implantação de cânulas ruminais permanentes, segundo a técnica descrita por MUZZI et al. (2009). Foi instituído intervalo pósoperatório de quatro semanas para completa recuperação e adaptação dos animais. Nesse período e durante toda a fase experimental, os ovinos receberam dieta diária à base de farelo de soja $(150 \mathrm{~g}$ por animal), oferecida duas vezes ao dia, às $8: 00 \mathrm{~h}$ e 16:00h; além de capim elefante (Pennisetum purpureum) e tifton (Cynodom sp), sal mineral e água ad libitum.

Os ovinos foram subdivididos em dois grupos de sete animais; um grupo controle e o outro que recebeu a salinomicina ${ }^{1}$ administrada diretamente no rúmen, através da fístula, na dose diária de $30 \mathrm{mg} / \mathrm{kg}$ da dieta, por animal, no decorrer de 42 dias (MERCHEN \& BERGER, 1985). Após a recuperação cirúrgica dos animais, dois dias antes da indução, avaliaram-se os parâmetros clínicos e coletou-se o fluido ruminal. $\mathrm{O}$ exame físico e a colheita das amostras para os exames laboratoriais foram realizados, com a finalidade de se estabelecer os valores médios do padrão fisiológico (momento controle - 0h) para as variáveis estudadas. Após o período inicial de adaptação, a aplicação do antibiótico foi mantida e a acidose foi induzida fornecendo-se como substrato $10 \mathrm{~g}$ de sacarose $/ \mathrm{kg}$ de peso corpóreo, através da fístula ruminal, às oito horas da manhã, antes da alimentação matinal (DELAK \& ADAMIC, 1959). As observações clínicas no decorrer do experimento e a colheita das amostras do fluido ruminal foram efetuadas em intervalos de $4 \mathrm{~h}, 8 \mathrm{~h}, 12 \mathrm{~h}, 16 \mathrm{~h}, 24 \mathrm{~h}, 32 \mathrm{~h}$, e $48 \mathrm{~h}$ pósindução (PI), a fim de que fosse observado o surgimento das alterações clínicas e laboratoriais indicativas de acidose lática, de acordo com as recomendações de KEZAR \& CHURCH (1979) e RADOSTITS et al. (2007).

As amostras do conteúdo ruminal foram obtidas por meio de uma bomba de sucção a vácuo, acoplada a uma sonda plástica flexível inserida através da cânula ruminal. Aproximadamente 200 $\mathrm{mL}$ de líquido ruminal foram colhidos em cada amostra, em frascos de vidro, para serem processadas no laboratório. O início da realização das provas não ultrapassou o tempo máximo de 15 minutos após a colheita.

A análise dos aspectos físicos cor, odor, consistência, $\mathrm{pH}$, bem como as provas de redução do azul de metileno (PRAM), acidez titulável (ATT) e o teor de cloretos foram realizados de acordo com as

$1 *$ Salocin 120 - Intervet. 
técnicas descritas por VIEIRA et al. (2007).

A observação da porcentagem de vivos, densidade e motilidade dos infusórios além da avaliação da flora bacteriana foram realizadas pelo exame direto em lâmina, empregando-se o modelo proposto por DIRKSEN (1993). Na contagem dos infusórios, utilizou-se a técnica recomendada por DEHORITY (1977).

Os valores obtidos foram analisados ao longo dos momentos, comparando-se os efeitos dos sete momentos PI com o momento controle e entre grupos, empregando-se nas variáveis - frequência cardíaca, frequência respiratória, temperatura retal e teor de cloretos do fluido ruminal - o método estatístico da análise de variância, com realização dos contrastes entre médias pelo método de Tukey e a estatística $\mathrm{F}$ calculada considerada significativa a $5 \%$. Para a análise das variáveis porcentagem de protozoários vivos, contagem, densidade, motilidade, $\mathrm{pH}$, prova de redução do azul de metileno e acidez total titulável do fluido ruminal, obteve-se a mediana como medida de tendência central e utilizou-se o método analítico não paramétrico de Friedman para amostras dependentes e o método de Mann Whitney para amostras independentes, usando $0 \quad \mathrm{X}^{2} \mathrm{e}$ calculando-se a dms para alfa igual a 0,05 , com o intuito de verificar se existiam diferenças significativas entre os valores (SAMPAIO, 2010).

\section{RESULTADOS}

A indução da acidose nos ovinos, administrando-se sacarose por via ruminal na quantidade $10 \mathrm{~g} / \mathrm{kg}$ de peso corporal, provocou um quadro de acidose ruminal branda, desencadeando manifestações clínicas com intensidade variada. Ao exame físico, observaram-se sinais de inapetência, anorexia, apatia, taquicardia (Figura 1), distensão do abdômen, hipomotilidade e/ou atonia do rúmen e ausência da ruminação. As fezes não chegaram a ser diarréicas, mas ficaram com aspecto de agrupadas a pastosas. Houve variação de um grau na desidratação, mas apenas em alguns animais, não sendo clinicamente relevante. $O$ quadro de timpanismo não foi observado. Esses sinais se tornaram evidentes a partir de $8 \mathrm{~h} \mathrm{PI}$; entretanto, na maioria dos ovinos, verificou-se o restabelecimento do quadro clínico a partir de 32h PI. Não ocorreu diferença estatística $(\mathrm{P}>0,05)$ nos grupos nem entre eles.

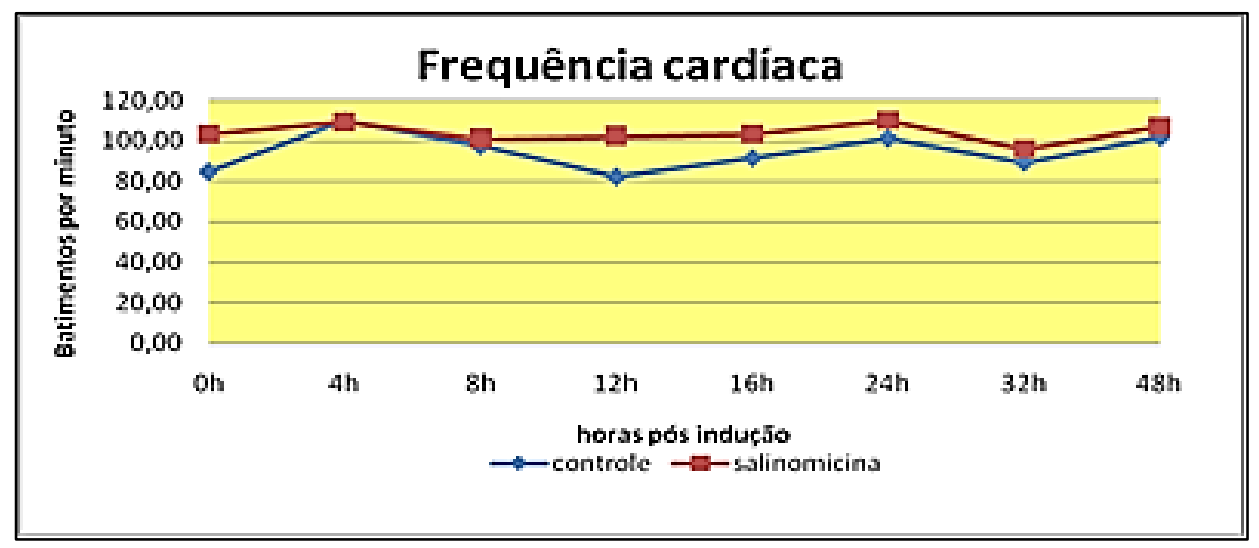

Figura 1. Valores médios da frequência cardíaca (bpm), dos ovinos do grupo controle e da salinomicina, com acidose láctica ruminal induzida com sacarose $(10 \mathrm{~g} / \mathrm{Kg}$ de peso corpóreo), nos momentos analisados.

As alterações da cor, odor e consistência do suco ruminal dos ovinos com acidose ruminal iniciaram-se a partir de 4h PI com maior intensidade 8h PI.

A cor modificou-se de verde-oliva ou castanha para amarela leitosa, mantendo-se alterada até as 16 PI. A partir desse momento, o fluido começou a voltar à coloração normal, restabelecendo-se no grupo controle às $32 \mathrm{~h} \mathrm{PI}$; todavia, no grupo da salinomicina, o tempo de recuperação dessa variável foi mais precoce, tendo seu retorno às 24 horas PI na maior parte dos animais.

O odor aromático tornou-se adocicado, chegando a ácido, entre os momentos $8 \mathrm{~h}$ e $16 \mathrm{~h}$ PI no grupo salinomicina; contudo, no momento $32 \mathrm{~h}$ PI ainda encontrava-se alterado na maioria dos animais do grupo controle e apenas 48h PI a recuperação foi praticamente total. Vale salientar que em apenas um animal do grupo controle, no momento $16 \mathrm{~h}$ PI, foi detectado odor pútrido.

A consistência modificou sua característica 
tornando-se aquosa, entre os momentos $8 \mathrm{~h}$ e $16 \mathrm{~h}$ PI. Entretanto, o restabelecimento foi observado a partir de 24horas PI em ambos os grupos analisados.

A indução provocou nos grupos controle e da salinomicina uma redução progressiva nos valores do $\mathrm{pH}$ do fluido ruminal, de maneira mais expressiva às 8 horas PI, obtendo-se valores de 6,06 e 6,07, respectivamente, havendo diferença significativa $(\mathrm{P}<0,05)$ em relação ao momento controle ( 0 hora). Com a evolução do processo fermentativo, verificou- se que os índices de $\mathrm{pH}$ elevaram-se, alcançando, no último momento de observação, valores próximos aos da normalidade. Há de se relatar que não existiram diferenças significativas $(\mathrm{P}>0,05)$ entre os grupos nos diferentes momentos de observação. Todavia, constatou-se que os animais do grupo da salinomicina tiveram recuperação mais precoce nos momentos seguintes de observação, em relação aos do grupo controle (Figura 2).

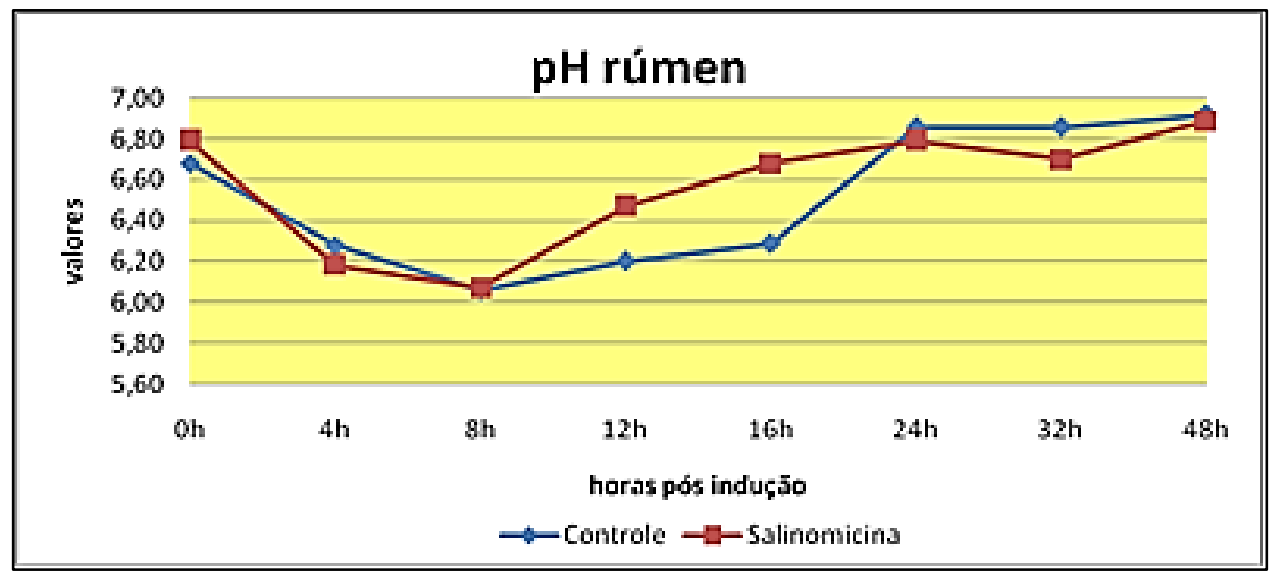

Figura 2. Valores da mediana do $\mathrm{pH}$ do fluído ruminal dos ovinos do grupo controle e da salinomicina, com acidose láctica ruminal induzida com sacarose $(10 \mathrm{~g} / \mathrm{Kg}$ de peso corpóreo), nos momentos analisados.

Nos ovinos estudados, a acidose ruminal causou alteração nos valores da acidez titulável do fluido ruminal, em relação aos valores de $0 \mathrm{~h}$ e, durante essa manifestação clínica, ocorreu elevação significativa $(\mathrm{P}<0,05)$ desta variável a partir das $4 \mathrm{~h}$
PI, alcançando o valor máximo de $48^{\circ} \mathrm{UC}$ às $4 \mathrm{~h}$ PI no grupo da salinomicina e às $8 \mathrm{~h}$ PI no grupo controle (Figura 3). Não foram verificadas diferenças significativas $(\mathrm{P}>0,05)$ entre os grupos para esta variável ao longo dos momentos analisados.

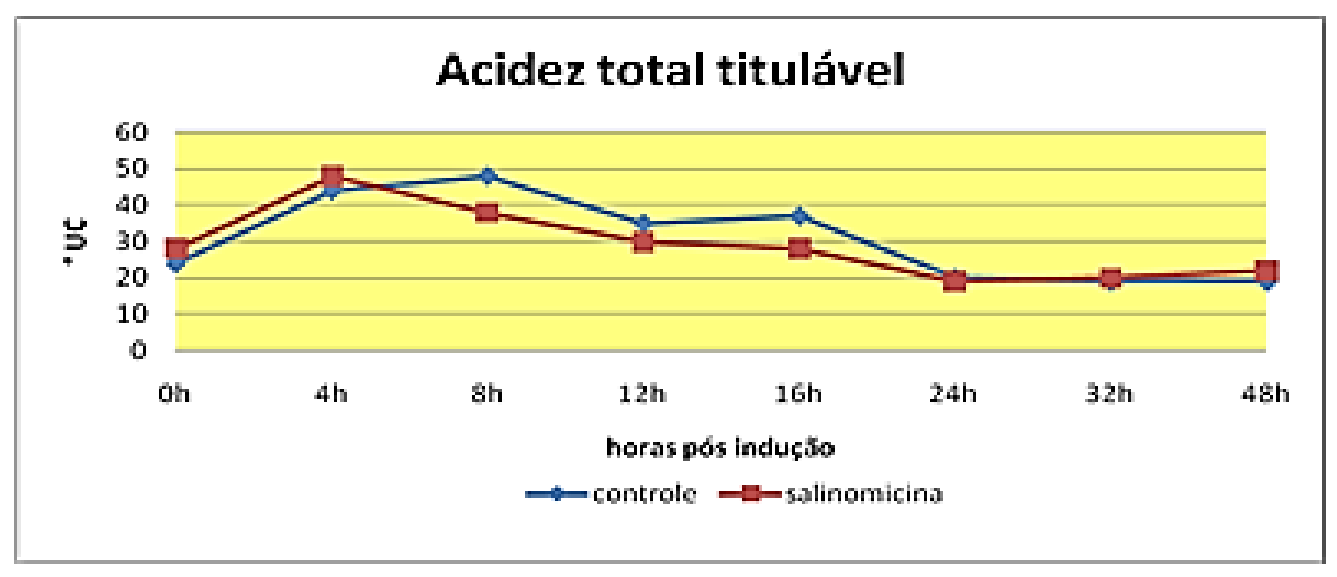

FIGURA 3. Valores da mediana da acidez total titulável do fluído ruminal dos ovinos do grupo controle e da salinomicina, com acidose láctica ruminal induzida com sacarose $(10 \mathrm{~g} / \mathrm{Kg}$ de peso corpóreo), nos momentos analisados. 
$\mathrm{O}$ teor de cloreto no fluido ruminal dos ovinos com acidose láctica apresentou redução dos seus valores ao longo do tempo de observação. Constataram-se os menores valores de 17,78 e 19,08 $\mathrm{mEq} / \mathrm{L}$ 12h PI para os grupos da salinomicina e controle, respectivamente. Não houve diferença significativa $(P>0,05)$ entre os grupos nos diferentes momentos de observação. Ao final ocorreu o restabelecimento desta variável aos valores iniciais em ambos os grupos.

Os valores obtidos na PRAM demonstraram que, após a indução da acidose láctica ruminal, ocorreu elevação no tempo de redução da prova, observando-se que não foi significativa no grupo da salinomicina, às $8 \mathrm{~h}$ PI, e no grupo controle, às $16 \mathrm{~h}$ PI, quando comparados com o momento controle (0h). Entretanto, observou-se que ocorreu uma recuperação da atividade da flora bacteriana mais precoce nos animais que receberam a salinomicina em relação ao controle a partir das 12 horas PI.

Após a indução da acidose, constatou-se haver alteração quantitativa na contagem de infusórios no fluido ruminal dos ovinos. Verificou-se a ocorrência de um declínio significativo $(\mathrm{P}<0,05)$ no número de infusórios logo nos primeiros momentos, às $4 \mathrm{~h} \mathrm{PI}$, no grupo controle, que se manteve em todos os momentos de observação, quando comparado ao momento inicial (0h); já o grupo da salinomicina apresentou alterações significativas $(\mathrm{P}<0,05)$ entre $12 \mathrm{~h}$ e $16 \mathrm{~h} \mathrm{PI}$, em relação ao momento inicial. Quando comparados os dois grupos nos diferentes momentos de observação, não houve diferença significativa $(P>0,05)$. Em todos os animais, antes da indução, existiu uma maior prevalência de pequenos infusórios, em torno de $60 \%$, e o restante era composto pelos médios e grandes. Vale ressaltar que, durante a fase da acidose, surgiram modificações na população dos infusórios, constatando-se predomínio dos pequenos (80\%) em relação aos médios e grandes, que se mostraram mais sensíveis às alterações ocorridas no ambiente ruminal.

Os resultados observados na porcentagem de infusórios vivos foram de queda mais acentuada nos momentos das $8 \mathrm{~h}$ e $12 \mathrm{~h}$ PI, quando não foi observado nos grupos nenhum infusório viável, apresentando alterações significativas $(\mathrm{P}<0,05)$, em relação ao momento controle $0 \mathrm{~h}$ em todos os momentos de observação. Não foi constatada diferença significativa $(\mathrm{P}>0,05)$ entre os grupos nos diferentes momentos de observação. Entretanto, verificou-se restabelecimento gradual dessa característica no fluido ruminal a partir das $16 \mathrm{~h}$ PI no grupo da salinomicina em relação ao grupo controle; neste segundo grupo os infusórios tiveram restabelecimento gradual a partir das $48 \mathrm{~h} \mathrm{PI}$.
Após a indução da acidose, verificou-se diminuição significativa $(\mathrm{P}<0,05)$ na densidade da microfauna, que atingiu valores mínimos a partir das 8h PI até o último momento de observação no grupo controle e das $8 \mathrm{~h}$ até $12 \mathrm{~h}$ no grupo da salinomicina. Vale ressaltar que não houve ausência dos infusórios, que ficaram apenas escassos, com a densidade considerada como um. Não houve diferença significativa $(\mathrm{P}>0,05)$ entre os grupos nos diferentes momentos de observação.

Com o início do distúrbio fermentativo constatou-se uma diminuição da motilidade, com diferenças significativas $(\mathrm{P}<0,05)$ em todos os momentos do grupo controle, quando comparado ao momento $\mathrm{Oh}$; todavia, no grupo da salinomicina houve diferença significativa $(\mathrm{P}<0,05)$ apenas no momento 8h PI. Não foi constatada diferença $(\mathrm{P}>0,05)$ entre os grupos ao longo dos momentos.

A indução, apesar de ter provocado um quadro clínico de acidose branda, modificou o padrão morfo-tintorial da população bacteriana do fluído ruminal nos animais dos grupos estudados, sendo que a alteração mais evidente no grupo da salinomicina foi o predomínio de bactérias Grampositivas (60-70\%) no período das $8 \mathrm{~h} \mathrm{PI}$, quando observaram-se estruturas de cocos e cocobacilos, enquanto no grupo dos animais controle essa manifestação foi mais intensa e duradoura, observada nos momentos 8 a 16h PI. Ao final do período de observação, em ambos os grupos, ocorreu o restabelecimento do padrão quando comparado ao momento controle.

\section{DISCUSSÃO}

Os sinais clínicos observados nos animais com acidose induzida neste experimento foram muito similares aos descritos em outros modelos, quando diferentes tipos de substratos e espécies animais foram utilizados. Os achados clínicos típicos de acidose láctica ruminal ocorreram em alguns dos momentos, mas, de forma geral, os animais reduziram o apetite, com diminuição da dinâmica ruminal, desidratação, poliúria, discreta taquicardia em poucos animais, as fezes modificaram seu aspecto para pastosas, ocorreu o consumo frequente de água, discreta ou ausência de distensão abdominal, ou seja, ocorreu uma acidose láctica de pouca intensidade. Tais manifestações coincidiram com a diminuição no $\mathrm{pH}$ do fluido ruminal, principalmente quando os valores estavam no seu ponto mais baixo, o que também foi observado por MUIR et al. (1980), CRICHLOW (1989), OWENS et al. (1998), METKARI et al. (2001), MIRANDA NETO et al. (2005), NAGARAJA \& LECHTENBERG (2007), ALMEIDA et al. (2008) e 
COMMUN et al. (2009), que relataram essa diminuição em razão do aumento da concentração de ácido lático e da osmolaridade do meio ruminal em relação à corrente sanguínea, desencadeando as alterações clínicas descritas.

Em relação ao apetite, o grupo controle apresentou maior número de animais com apetite diminuído e/ou ausente de 8h PI até 32h PI, enquanto no grupo salinomicina, o comprometimento do apetite só ocorreu entre os momentos $12 \mathrm{~h}$ e $32 \mathrm{~h}$ PI e em menor número de animais. Isso demonstra o aspecto favorável do uso da salinomicina no grupo tratado frente aos efeitos deletérios da acidose láctica quando comparado aos animais que não receberam o ionóforo, concordando com os relatos de KEZAR \& CHURCH (1979), AFONSO et al. (2002b), MIRANDA NETO et al. (2005) e LEAN et al. (2007), que correlacionam a recuperação da ingestão normal de alimentos com um ambiente ruminal favorável, em que o pH seja maior que seis, não haja ácido lático em níveis detectáveis ou sua concentração seja mínima, e que as concentrações dos ácidos graxos voláteis (AGV) apresentem valores acima de $50 \mathrm{mM}$.

Quanto ao tempo de recuperação clínica, os animais do grupo do ionóforo iniciaram o retorno à normalidade de forma mais precoce, quando comparado ao grupo controle, que necessitou de um intervalo de tempo maior para o restabelecimento, semelhante às observações de BEED \& FARLIN (1977), AFONSO et al. (2000) e MIRANDA NETO et al. (2011), exceto quanto ao intervalo de tempo no surgimento das manifestações clínicas, em relação aos picos máximos dos índices baixos de $\mathrm{pH}$ e lactato ruminal após a indução, provavelmente devido ao modelo experimental e variações da espécie utilizada, além do tipo de indução diferente.

As modificações das características físicas do fluido ruminal observadas foram marcantes durante o período de acidose ruminal nos ovinos, como a cor, tornando-se pouco leitosa a leitosa, a consistência aquosa e o odor de pouco adocicado a ácido. Esses achados condizem com os encontrados por alguns autores que relacionam as alterações com a diminuição do $\mathrm{pH}$ no rúmen, causada pela excessiva elevação na concentração do ácido lático e $\mathrm{AGV}$, que aumenta a osmolaridade do meio, tornando-o hipertônico em relação ao plasma, provocando maior fluxo de água dos compartimentos intra e extracelulares para o interior do trato digestivo, principalmente ao rúmen (JUHÁSZ \& SZEGEDI, 1968; DOUGHERTY et al., 1975 e BRAUN et al., 2010). Essas mudanças iniciaram-se a partir de 8h PI e foram semelhantes às manifestações observadas em caprinos e ovinos com acidose ruminal estudadas por HUBER (1971), CAO et al.
(1987), LEAN et al. (2007) e ALMEIDA et al. (2008). O restabelecimento dessas características acompanhou a recuperação do $\mathrm{pH}$ aos valores anteriores à indução.

Quanto ao declínio nos valores do $\mathrm{pH}$ ruminal no início do processo, devido à administração da sacarose e sua rápida fermentação, há relatos, como os de JUHÁSZ \& SZEGEDI (1968), OWENS et al. (1998) e BROSSARD et al. (2003), que atribuem esses achados às modificações da microflora ruminal, em que as bactérias Gramnegativas, sensíveis à acidez do meio, são substituídas pelas Gram-positivas, principalmente o S. bovis e o Lactobacillus sp., que são as principais produtoras do ácido lático, nas formas $\mathrm{L}(+)$ e $\mathrm{D}(-)$, o qual é considerado como um ácido forte, por possuir uma $\mathrm{p}$ Ka muito baixa.

Apesar de não ter havido diferença significativa entre os grupos, notou-se que o grupo da salinomicina teve recuperação mais precoce em relação ao grupo controle, fato também relatado por NAGARAJA et al. (1981) e NAGARAJA et al., (1982), que, ao usarem lasalocida ou monensina na prevenção da acidose láctica, verificaram uma diminuição dos AGV's, bem como do lactato $\mathrm{D}(-)$ e $\mathrm{L}(+)$, elevando o $\mathrm{pH}$ do meio, que foi o motivo para sua prevenção, justificando a eficácia pela ação do antibiótico sobre a população de bactérias Grampositivas, produtoras de ácido lático, e o favorecimento da flora Gram-negativa (GOAD et al., 1998; McGUFFEY et al., 2001; GUO et al., 2010). Criando-se uma melhoria no ambiente ruminal, principalmente quanto ao $\mathrm{pH}$, favorecendo dessa maneira o retorno do apetite, melhorou-se o tamponamento e a restauração da população microbiana, facilitando a recuperação clínica.

Os valores da acidez total apresentaram-se elevados nos animais induzidos, corroborando os achados de DIRKSEN (1993), que cita índices de 8 a $26^{\circ} \mathrm{UC}$ como normais e que, no caso da acidose ruminal, tais valores podem alcançar 70 unidades ou mais, dependendo do grau de hiperacidez existente no meio. Essa alteração reflete a redução observada no $\mathrm{pH}$ ruminal logo nos primeiros momentos em função do aumento do nível de ácido láctico presente no fluido ruminal (AFONSO et al., 2002b). Com o passar do tempo, ocorreu a elevação do $\mathrm{pH}$, provavelmente devido à diminuição do lactato, de forma mais rápida no grupo dos ovinos tratados com o antibiótico, em relação ao seu controle. Isso se deve à habilidade dos compostos ionóforos de modular os efeitos da acidose e alterar o padrão da fermentação ruminal, reduzindo os danos provocados pela intensidade e duração do $\mathrm{pH}$ baixo no rúmen, e por inibir de forma seletiva as bactérias rumenais Gram positivas, maiores produtoras de ácido láctico 
(NAGARAJA et al., 1981; McGUFFEY et al. 2001; BUTAYE et al., 2003).

As alterações no teor de cloretos ocorreram já nos momentos iniciais, provavelmente, pelo decréscimo do $\mathrm{pH}$ no fluido ruminal, notado a partir da administração da sacarose. Essa diminuição foi verificada após $8 \mathrm{~h}$ de indução, coincidindo com as observações dos trabalhos realizados por HUBER (1971), em ovinos, e por CAO et al. (1987), MIRANDA NETO et al. (2005) e MIRANDA NETO et al., 2011) em caprinos induzidos a ter acidose com diferentes substratos. Esses autores a ocorrência dessa alteração devido ao aumento do gradiente osmótico, que acarretou o sequestro de líquido da corrente sanguínea para o interior do rúmen, causando uma diluição exacerbada do fluido ruminal e, com isso, reduziu a concentração desse íon. Entretanto, no decorrer do experimento, observou-se que a concentração de cloretos sofreu elevação, fato que provavelmente está relacionado com o menor volume de líquido em relação à matéria seca do conteúdo ruminal daqueles animais que tiveram sinais clínicos de diarréia e desidratação. Um fator complicador para essa ocorrência, segundo OWENS et al. (1998), é que a alta osmolaridade do fluido ruminal durante a acidose provoca também hipertonicidade do abomaso, tornando-o distendido, diminuindo o trânsito do bolo alimentar e dificultando a remoção do fluido e dos ácidos do rúmen. $\mathrm{O}$ refluxo do conteúdo abomasal, devido à sua inércia, foi citado por BRAUN et al. (1992) como sendo a causa do aumento nas concentrações de cloreto $(>25 \mathrm{mmol} / \mathrm{l})$ no fluido ruminal, em $42 \%$ dos ovinos e caprinos diagnosticados com acidose ruminal aguda.

O comprometimento da flora ruminal, observado no tempo de redução da prova do azul de metileno, em alguns animais, durante a manifestação da acidose, foi semelhante aos relatados por BASAK et al. (1993) e QUIROZ-ROCHA \& BOUDA (2000), que justificaram essa alteração devido à inativação da flora normal, que fica com metabolismo comprometido, quando as condições do meio estão adversas. A restauração do ambiente ruminal nos ovinos foi mais uma vez determinante para que essa variável retornasse aos valores normais estabelecidos inicialmente, de forma mais precoce no grupo da salinomicina. Uma condição que contribui para esse processo foi descrita por AFONSO et al. (2002b), em que o uso de monensina inibe a maioria das bactérias ruminais produtoras de lactato, mas não as bactérias que fermentam.

As alterações na fauna microbiana do fluido ruminal dos ovinos estudados com relação à diminuição da viabilidade, densidade, motilidade e contagem dos infusórios ocorreram em momentos distintos, com intensidade variada, mostrando um grau de recuperação maior nos animais do grupo da salinomicina. Essas alterações foram citadas por AFONSO et al. (2002b), que constataram, em trabalho realizado com ovinos, que a população de protozoários diminuiu extensivamente com o aumento da acidez no rúmen, chegando a ocorrer defaunação, diferindo dos nossos achados em relação à intensidade do processo fermentativo. De acordo com HUNGATE et al. (1952), os protozoários perdem a sua atividade quando o $\mathrm{pH}$ cai para valores entre 5,5 e 5,0, desintegrando-se ou sofrendo lise no rúmen quando ocorre uma elevação da acidez do meio, e o pH alcança valores inferiores a 5,0. AHUJA et al. (1990) relataram, ainda, que o aumento da pressão osmótica no ambiente ruminal causa alterações na população de protozoários. Ao final das observações, verificou-se que, em alguns dos ovinos que receberam a salinomicina, ocorreu o reaparecimento da fauna e o restabelecimento de suas funções, o que condiz com as informações de BASAK et al. (1993), que relataram essa manifestação sincronizada com a melhoria do $\mathrm{pH}$ no rúmen.

Como foi observada, a modificação qualitativa no padrão morfotintorial da população bacteriana ocorreu devido à diminuição do $\mathrm{pH}$. Com isso, a flora predominantemente Gram-negativa foi parcialmente substituída, em alguns dos momentos, por bactérias Gram-positivas, como relatado por OWENS et al. (1998) e MIRANDA NETO et al. (2005), que afirmaram que, com a evolução da enfermidade, há uma alteração na população microbiana, caracterizada pelo rápido crescimento das bactérias produtoras de ácido láctico, que se acumula em quantidades suficientes para reduzir o $\mathrm{pH}$ ruminal a valores bem críticos $(\mathrm{pH}<5,0)$. Nesse ambiente, a concentração e a atividade de muitas bactérias fisiologicamente importantes são bastante reduzidas, provocando um predomínio das bactérias Gram positivas sobre as Gram negativas.

$\mathrm{O}$ retorno à normalidade da população microbiana no fluido ruminal ocorreu, de forma gradual com o subsequente crescimento da flora Gram negativa, especialmente pequenos cocos, que prevaleceram no meio. Essas alterações manifestaram-se, principalmente, de forma mais antecipada, no grupo que recebeu o ionóforo e isso se deve provavelmente ao fato de a salinomicina exercer um efeito inibitório sobre as bactérias Gram positivas, sendo que esse achado coincide com o intervalo de tempo em que a produção do ácido láctico diminuiu e o $\mathrm{pH}$ se elevou no fluido ruminal (NAGARAJA et al., 1982; NAGARAJA et al., 1985; AFONSO et al., 2002b). 


\section{CONCLUSÕES}

A salinomicina fornecida aos ovinos, na dose estabelecida, não previne a acidose lática ruminal induzida com o uso da sacarose. Entretanto, efetivamente, os efeitos adversos deste distúrbio são minimizados, ou seja, a severidade da acidose é reduzida na sua intensidade e no tempo de evolução, tornando a recuperação mais precoce nos animais que receberam o ionóforo.

\section{REFERÊNCIAS}

AFONSO, J.A.B.; CIARLINI, P.C.; KUCHEMBUCK, M.R.G.; KOHAYAGAWA, A.; FELTRIN, L.P.Z.; CIARLINI, D.R.P.; LAPOSY, C.B.; MENDONÇA, C.L.; TAKAHIRA, R.K. Metabolismo oxidativo dos neutrófilos de ovinos tratados com a monensina sódica e experimentalmente submetidos à acidose ruminal. Pesquisa Veterinária Brasileira, v.22, n.4, p.129-134, 2002a.

AFONSO, J.A.B.; KUCHEMBUCK, M.R.G.; FELTRIN, L.P.Z.; LAPOSY, C.B.; KOHAYAGAWA, A.; MENDONÇA, C.L.; TAKAHIRA, R.K. Efeito da monensina sódica sobre as características do suco ruminal na acidose láctica ruminal experimental em ovinos. Revista Brasileira de Medicina Veterinária, v.24, n.5, p.203-210, 2002b.

AFONSO, J.A.B.; MENDONÇA, C.L.; FIORAVANTE, M.C.S.; KUCHEMBUCK, M.R.G. Características e indicações clínicas dos ionóforos para ruminantes. Revista do Conselho Federal de Medicina Veterinária, v.6, n.20, p.29-36, 2000.

AHUJA, A. K.; RANDHAWA, S.S.; RATHOR, S.S. Effect of monensina in ameliorating subacute lactic acidosis in buffalo calves. Acta Veterinaria Brno, v.59, p.171-178, 1990.

ALMEIDA, M.Z.P.R.B.; MENDONÇA, C.L.; AFONSO, J.A.B.; MIRANDA NETO, EG. Estudo clínico, hematológcio e bioquímico em caprinos submetidos à acidose láctica ruminal induzida experimentalmente. Veterinária e Zootecnia, v.15, n.1, p.100-113, abr 2008.

BARROS, N.N.; SIMPLÍCIO, A.A.; FERNANDES, F.D. Terminação borregos em confinamento. Circular técnicaEmbrapa- Sobral. 1999. 24p.

BASAK, D.N.; SPAN, S.; CHAKRABARTI, A. Physicochemical and microbial changes in rumen liquor of experimentally induced lactic acidosis in goats. Indian Journal of Animal Science, v.63, p.263-67, 1993.

BEED, D.K.; FARLIN, S.D. Effects of capreomycin disulfate and oxamycin on ruminal $\mathrm{pH}$ lactate and volatile fatty acid concentration in sheep. Journal of Animal Science, v.45, n.2, p.393-401, 1977.

BRAUN, J.P; TRUMEL, C.; BÉZILLE, P. Clinical biochemistry in sheep: A selected review. Small
Ruminant Research, v.92, p.10-18, 2010.

BRAUN, U.; RIHS, T.; SCHEFER, U. Ruminal lactic acidosis in sheep and goats. Veterinary Record, v.130, p.343-349, 1992.

BROSSARD, L.; MARTIN, C.; MICHALET-DOREAU, B. Ruminal fermentative parameters and blood acid-basic balance changes during the onset and recovery of induced latent acidosis in sheep. Animal Research, v.52, p.513530, 2003.

BUTAYE, P.; DEVRIESE, L.A.; HAESEBROUCK, F. Antimicrobial growth promoters used in animal feed: effects of less well known antibiotics on Gram positive bacteria. Clinical Microbiology Reviews, v.16, p.175178, 2003.

CAO, G.R.; ENGLISH, P.B.; FILIPPICH, L.J.; ONGLIS, $\mathrm{S}$. Experimentally induced lactic acidosis in the goat. Australian Veterinary Journal, v.64, n.12, p.367-370, 1987.

CRICHLOW, E. C. Loss of forestomach motility in sheep experiencing ruminal lactic acidosis is not dependent on duodenal acidification on by lactic acid. Zent Veterinary Archiv, v.36, p.39-45, 1989.

COMMUN, L.; MIALON, M.M.; MARTIN, C.; BAUMONT, R.; VEISSIER, I. Risk of subacute ruminal acidosis in sheep with separate access to forage and concentrate. Journal of Animal Science, v.87, p.33723379, 2009.

DEHORITY, B. A. Classification and morphology of rumen protozoa. Ohio: Departament of Animal Science, 1977, 81p.

DELAK, M.; ADAMIC, S. Contribution to the knowledge of saccharose intoxication in sheep. Veterinary Archiv, v.29, p.214-222, 1959.

DIRKEN, G. Sistema digestivo. In.: DIRKSEN, G.; GRÜNDER, H.D., STÖBER, M. Rosemberger exame clínico dos bovinos. 3 ed, Rio de Janeiro. Guanabara Koogan, p. 166-228, 1993.

DOUGHERTY, R W.; RILEY, J.L.; COOK, H.M. Changes in motility and $\mathrm{pH}$ in the digestive tract of experimentally overfeed sheep. Amrican Journal of Veterinary Research, v.36, p.827-829, 1975.

GOAD, D.W.; GOAD, C.L.; NAGARAJA, T.G. Ruminal microbial and fermentative changes associated with experimentally induced subacute acidosis in steers. Journal of Animal Science, v.76, p.234-241, 1998.

GUO, T.J.; WANG, J.Q.; LIU, K.L.; WANG, J.P.; LI, D.; LUAN, S.Y.; HUO, X.K. Evaluation of the microbial population in ruminal fluid using time PCR in steers treated with virginiamycin. Czech Journal of Animal Science, v.55, n.7, p.276-285, 2010.

HUBER, T. L. Effect of acute indigestion on comportamental water volume and osmolality in sheep. American Journal of Veterinary Research, v.32, n.6, p.887-890, 1971. 
HUNGATE, R.E.; DOUGHERTY, R.W.; BRYANT, M.P.; CELLO, R.M. Microbiological and physiological changes associated with acute indigestion in sheep. Cornell Veterinary, v.42, p.423-449, 1952.

IBGE - Instituto Brasileiro de Geografia e Estatística. Rebanho ovino - efetivo por Região. 2012. www.ibge.gov.br/home/estatistica/economia/ppm/2011/de fault_pdf.shtm

JUHÁSZ, B.; SZEGEDI, B. Pathogenesis of rumen overload in sheep. Acta Physiologica Hungary, v.18, p.63-80, 1968.

KEZAR, W.W.; CHURCH, D.C. Ruminal changes during the onset and recovery of induced lactic acidosis in sheep. Journal of Animal Science, v.49, n.5, p.1161-1167, 1979.

LEAN, I.J.; ANNISON, F.; BRAMLEY, E.; BROWNING, G.; CUSACK, P.; FARQUHARSON, B.; LITTLE, S.; NANDAPI, D. Ruminal acidosis understandings, prevention and treatment. Australia. Australian Veterinary Association, 2007, 52p.

McGUFFEY, R.K.; RICHARDSON, L.F.; WILKINSON, J.I.D. Ionophores for dairy cattle: Current status and future outlook. Journal of Dairy Science, v. 84, p.194-203, 2001.

MACKIE, R.I.; GILCHRIST, F.M.C.; ROBBERTS, A.M.; HANNAH, P.E.; SCHWARTZ, H.M. Microbiological and chemical changes in the rumen during the stepwise adaptation of sheep to high concentrate diets. Journal of Agriculture and Science, v.90, p.241-254, 1978.

MERCHEN, N.R.; BERGER, L.L. Effect of salinomicin level on nutrient digestibility and ruminal characteristics of sheep and feedlot performance of cattle. Journal of Animal Science, v. 60, n.5, p.1338-1346, 1985.

METKARI, S.M.; SALABAT, A.; RAJGURU, D.N.; SALEEM, M. Management of experimentally induced lactic acidosis in goats. Indian Veterinary Journal, v.78, p.692-694, 2001.

MIRANDA NETO, E.G.; SILVA, S.T.G.; MENDONÇA, C.L.; DRUMMOND, A.R.F.; AFONSO, J.A.B. Aspectos clínicos e a bioquímica ruminal de caprinos submetidos à acidose láctica experimental e suplementados ou não com monensina sódica. Pesquisa Veterinária Brasileira, v.31, p.416-424, 2011.

MIRANDA NETO, E.G.; AFONSO, J.A.B.; MENDONÇA, C.L.; ALMEIDA, M.Z.P.R.B. Estudo clínico e características do suco ruminal em caprinos com acidose láctica induzida experimentalmente. Pesquisa Veterinária Brasileira, v.25, p.73-78, 2005
MUIR, L.A.; RICKES, E.L.; DUQUETTE, P.F.; SMITH, G.E. Control of wheat induced lactic acidosis in sheep by thiopeptin and related antibiotics. Journal of Animal Science, v.50, p.47-53, 1980.

MUZZI, L.A.L.; MUZZI, R.A.L.; GABELLINI, E.L.A. Técnica de fistulação e canulação do rúmen em bovinos e ovinos. Ciência Agrotécnica, v.33, p.2059-2064, 2009.

NAGARAJA, T.G.; LECHTENBERG, K.F. Acidosis in feedlot cattle. Veterinary Clinics of Food Animals, v.23, p.333-350, 2007.

NAGARAJA, T.G.; AVERY, T.B.; GALITZER, S.J.; HARMOND, D.L. Effect of ionophore antibiotics on experimentally induced lactic acidosis in cattle. Journal of Animal Science, v.46, p.2444-2452, 1985.

NAGARAJA, T.G.; AVERY, T.B.; BARTLEY, E.E.; ROOF, S.K. Effect of lasalocid, monensina or thiopeptin on lactic acidosis in cattle. Journal of Animal Science, v.54, p.649-658, 1982.

NAGARAJA, T.G.; AVERY, T.B.; BARTLEY, E.E.; GALITZER, S.J. Prevention of lactic acidosis in cattle by lasalocid or monensin. Journal of Animal Science, v. 53, p.206-216, 1981.

NOCEK, J.E. Bovine acidosis implication on laminitis. Journal of Dairy Science, v.80, p.1005-1028, 1997.

OWENS, F.N.; SECRIST, D.S.; HILL, W.J.; GILL, D.R. Acidosis in cattle: A review. Journal of Animal Science, v. 76, p. 275-286, 1998.

QUIROZ-ROCHA， G.; BOUDA， J. Diagnóstico de indigestão simples, alcalose ruminal e intoxicação por uréia. In: GONZÁLEZ, F.H.D.; BORGES, J.B.; CECIM, M. (Eds). Uso de provas de campo e de laboratório clínico em doenças metabólicas e ruminais dos bovinos. Porto Alegre. Gráfica da Universidade Federal do Rio Grande do Sul, p.23-26, 2000.

RADOSTITS, O.M.; HINCHCLIFF, K.W.; BLOOD, D.C.; GAY, C.C. Veterinary Medicine-A textbook of the diseases of cattle, horses, sheep, pigs and goats, $10^{\text {th }}$ ed. St Louis: Saunders, 2007. 2156p.

SAMPAIO, I.B.M. Estatística aplicada à experimentação animal. Belo Horizonte: Fundação de Ensino e Pesquisa em Medicina Veterinária e Zootecnia, 2010, 264p.

VIEIRA, A.C.S.; AFONSO, J.A.B.; MENDONÇA, C.L. Características do fluído ruminal de ovinos Santa Inês criados extensivamente em Pernambuco. Pesquisa Veterinária Brasileira, v. 27, n. 3, p.111-114, 2007.

WALKER, B. Grain poisoning of cattle and sheep. Prime Facts, n. 330, p.1-4, nov, 2006. 